\title{
Synthesis and Properties of Multi-Block Copolymers Based on Polybutadiene and Aromatic Polyamides Having Unsymmetrical Structures
}

\author{
Shin-ichi Ogata, Hiroyuki Maeda, Masa-aki KaKimoto, \\ and Yoshio IMAI \\ Department of Textile and Polymeric Materials, \\ Tokyo Institute of Technology, \\ Meguro-ku, Tokyo 152, Japan
}

(Received February 13, 1985)

\begin{abstract}
Polybutadiene-aramid multi-block copolymers having structural regularity were synthesized by a one-pot two-step method of direct polycondensation using triphenyl phosphite and pyridine as condensing agents. Amine-terminated telechelic aramid oligomers were prepared by the reaction of 3,4'-oxydianiline and isophthalic acid, and condensed with $\alpha, \omega$-polybutadienedicarboxylic acid giving the multi-block copolymers with inherent viscosities of $0.2-0.4 \mathrm{dlg}^{-1}$. They were soluble in a wide range of solvents including $N, N$-dimethylacetamide, pyridine, and tetrahydrofuran, and gave transparent, ductile, and elastomeric films by casting from the solutions of these solvents. Depression of the glass transition temperatures of polybutadiene phase in the multi-block copolymers was observed by increasing the aramid content. The tensile strength and modulus decreased with decreasing aramid content, whereas elongation at break increased.

KEY WORDS Polybutadiene-Aramid Multi-Block Copolymers /

Segmented Copolymers / Direct Polycondensation / Solubility / Thermal

Behavior / Glass Transition Temperature / Tensile Properties /

Transmission Electron Micrographs /
\end{abstract}

Our previous paper dealt with a convenient synthesis of polybutadiene-aromatic polyamide (aramid) multi-block copolymers by the direct polycondensation of liquid $\alpha, \omega$ polybutadienedicarboxylic acid (LPB-diacid) and amine-terminated telechelic aramid oligomers, using triphenyl phosphite and pyridine as condensing agents. ${ }^{1}$ Films of these multiblock copolymers had ductile and elastomeric properties owing to pseudo-crosslinked structures between the aramid blocks. These properties were also indicated by transmission electron micrographs, showing the micro phase separation of the polybutadiene and aramid phases.

Recently, at this laboratory, aramid I derived from 3,4'-oxydianiline $\left(3,4^{\prime}\right.$-ODA) and isophthalic acid (IPA) were found to be soluble in a wide range of solvents compared with aramid II obtained from 4,4'-oxydianiline (4,4'-ODA) and IPA. ${ }^{2}$ Although multi-block copolymers IV based on LPB-diacid and semirigid aramid II dissolved only in $\mathrm{N}, \mathrm{N}$-dimethylacetamide (DMAc), ${ }^{1}$ block copolymers III consisting of aramid I should be more readily soluble. Therefore, films of block copolymers cast from different solvents were expected to have different characteristics with respect to morphology and tensile properties.

In this article, the properties and microstructures of polybutadiene-aramid multiblock copolymers III derived from LPB-diacid and aramid I are discussed, and compared with those of block copolymers IV. 


$$
\begin{aligned}
& (\mathrm{x}+1) \mathrm{H}_{2} \mathrm{~N}-\mathrm{Ar}-\mathrm{NH}_{2}+\mathrm{x} \prod_{\mathrm{O}}^{\mathrm{HOC}}-\prod_{0}^{\mathrm{COH}} \\
& \stackrel{\mathrm{P}(\mathrm{OPh})_{3}}{\longrightarrow} \mathrm{H}_{2} \mathrm{~N}-\mathrm{Ar}-\mathrm{NH}(\underset{\mathrm{O}}{\mathrm{C}} \underset{\mathrm{O}}{\mathrm{CNH}-\mathrm{Ar}-\mathrm{NH}})_{\mathrm{X}} \mathrm{H} \\
& \text { I, II } \\
& \frac{\stackrel{\mathrm{O}}{\mathrm{HOC}}-\left(-\mathrm{CH}_{2} \mathrm{CH}=\mathrm{CHCH}_{2}\right)_{95} \stackrel{\mathrm{O}}{\mathrm{COH}}}{\mathrm{P}(\mathrm{OPh})_{3}+\mathrm{Py}}
\end{aligned}
$$

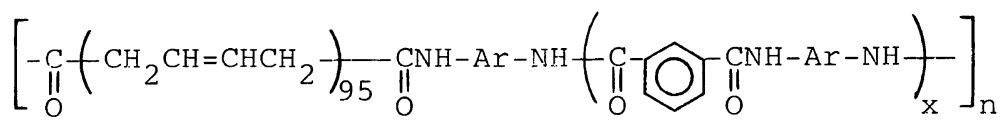

$$
\begin{aligned}
& \text { III, IV } \\
& \text { I, III : Arr=-OO } \\
& I I, I V: A r=\bigcirc-O-O
\end{aligned}
$$

\section{EXPERIMENTAL}

\section{Materials}

LPB-diacid ("Hycar CTB") was obtained from Goodrich $\mathrm{Co}$. The number average molecular weight was determined to be 5200 by titration. Its micro-structure was cis-1,4-, $22.1 \%$; trans-1,4-, 53.4\%; and 1,2-vinyl, $24.5 \%$.

IPA was purified by recrystallization from water. The diamines, 3,4'-ODA obtained from Teijin Ltd. and commercial 4,4'-ODA, were recrystallized from dichloromethane-hexane and tetrahydrofuran (THF), respectively. Triphenyl phosphite, pyridine, $N$-methyl-2-pyrrolidone (NMP), DMAc, and THF were purified by distillation. Other inorganic reagents were used as received.

\section{Synthesis of Multi-Block Copolymers}

Block Copolymer IIId. A mixture of $1.58 \mathrm{~g}$ $(7.89 \mathrm{mmol})$ of $3,4^{\prime}$-ODA, $1.23 \mathrm{~g}(7.39 \mathrm{mmol})$ of IPA, $6.20 \mathrm{~g}(20 \mathrm{mmol})$ of triphenyl phosphite, $0.33 \mathrm{~g}$ of lithium chloride, and $1.01 \mathrm{~g}$ of calcium chloride in $3.5 \mathrm{ml}$ of pyridine and $20 \mathrm{ml}$ of NMP was heated with stirring at $100^{\circ} \mathrm{C}$ for $2 \mathrm{~h}$ under nitrogen. To the reaction solution, $2.60 \mathrm{~g}(0.5 \mathrm{mmol})$ of LPB-diacid in $12.5 \mathrm{ml}$ of pyridine was added, and the mixture was stirred at $100^{\circ} \mathrm{C}$ for another $3 \mathrm{~h}$. The polymer was isolated by pouring the reaction mixture into $1000 \mathrm{ml}$ of methanol. The product was purified by reprecipitation from DMAcmethanol system, followed by successive washings with methanol and hexane. The yield of the polymer was $4.24 \mathrm{~g}(83 \%)$, and the inherent viscosity in DMAc was $0.40 \mathrm{dl} \mathrm{g}^{-1}$, measured at a concentration of $0.5 \mathrm{~g} \mathrm{dl}^{-1}$ at $30^{\circ} \mathrm{C}$. The IR spectrum (film) exhibited absorptions at $3300 \mathrm{~cm}^{-1}(\mathrm{~N}-\mathrm{H}), 1660 \mathrm{~cm}^{-1}(\mathrm{C}=\mathrm{O})$, and 965 and $910 \mathrm{~cm}^{-1} \quad(\mathrm{C}=\mathrm{C})$. Anal. Calcd for $\left(\mathrm{C}_{689} \mathrm{H}_{787} \mathrm{~N}_{32} \mathrm{O}_{47}\right)_{n}: \mathrm{C}, 80.53 \% ; \mathrm{H}, 7.66 \% ; \mathrm{N}$, $4.30 \%$. Found: C, $78.35 \%$; H, $6.88 \%$; 
$5.52 \%$.

Other multi-block copolymers IIIa-IIIc and IIIe, and copolymers IVa-IVe were prepared by analogous procedures.

\section{Measurements}

IR spectra were recorded on a Hitachi EPG3 spectrophotometer. Differential scanning calorimetry (DSC) was performed with a Daini Seikosha SSC-560 differential scanning calorimeter. Transmission electron microscopy was observed with a Hitachi HLT-12 electron microscope. Molecular weights of the polymers were determined with a Toyo Soda HLC-802 gel permeation chromatograph (GPC) and Uvigraph LC-1 UV detector, THF being used as eluent and polystyrene as calibration standards. Tensile properties were determined from stress-strain curves obtained with a Toyo Baldwin Tensilon UTM-III at an elongation rate of $33 \% \mathrm{~min}^{-1}$. Measurements were performed at room temperature with film specimens $(1.0 \mathrm{~cm}$ wide, $3.0 \mathrm{~cm}$ long, and about $0.1 \mathrm{~mm}$ thick) and the average of at least five individual determinations was taken.

\section{RESULTS AND DISCUSSION}

\section{Synthesis of Polybutadiene-Aramid Multi-}

Block Copolymers

Polybutadiene-aramid multi-block copolymers III were synthesized according to eq 1 by the one-pot two-step procedure reported previously. ${ }^{1}$ LPB-diacid used in this study had a number average molecular weight $\left(M_{n}\right)$ of 5200. The solutions of amine-terminated aramid oligomers I whose $M_{n}$ 's are $1200-8800$ were prepared first by the reaction of a calculated excess of 3,4'-ODA with IPA in the presence of triphenyl phosphite and pyridine in NMP. In the second step, LPB-diacid was added to the freshly prepared solution, and the polycondensation was continued under the same reaction conditions as those for the preparation of aramid oligomers. The polybutadiene-aramid multi-block copolymers having inherent viscosities of $0.23-0.43 \mathrm{dl} \mathrm{g}^{-1}$ were readily obtained (Table I). Weight average molecular weight $\left(M_{w}\right)$ and $M_{n}$ of block copolymer IIIa were estimated to be 200000 and 33000 , respectively, for standard polystyrene from GPC eluted by THF. The $M_{w} / M_{n}$ value was 6.0. The results of the synthesis of block copolymers IV are also shown in Table I for comparison.

In the IR spectra of the block copolymers III, characteristic amide absorptions at $3300 \mathrm{~cm}^{-1}(\mathrm{~N}-\mathrm{H})$ and $1655 \mathrm{~cm}^{-1}(\mathrm{C}=\mathrm{O})$, aromatic absorptions at 1600 and $1500 \mathrm{~cm}^{-1}$, and olefinic absorptions at 970 and $910 \mathrm{~cm}^{-1}$ appeared, whereas a strong carbonyl absorption at $1710 \mathrm{~cm}^{-1}$ due to the carboxylic function of the starting LPB-diacid disappeared.

Table I. Synthesis of polybutadiene-aramid multi-block copolymers III and IV

\begin{tabular}{|c|c|c|c|c|c|c|c|}
\hline \multicolumn{2}{|c|}{ Aramid } & \multicolumn{3}{|c|}{ Copolymer III } & \multicolumn{3}{|c|}{ Copolymer IV } \\
\hline $\mathrm{IPA} / \mathrm{ODA}^{\mathrm{a}}$ & \multirow{2}{*}{$M_{n}$} & \multirow{2}{*}{ Code } & \multirow{2}{*}{$\frac{\text { Yield }}{\%}$} & \multirow{2}{*}{$\frac{\eta_{\mathrm{inh}}^{\mathrm{b}}}{\mathrm{dl} \mathrm{g}^{-1}}$} & \multirow{2}{*}{ Code } & \multirow{2}{*}{$\frac{\text { Yield }}{\%}$} & \multirow{2}{*}{$\frac{\eta_{\mathrm{inh}}{ }^{\mathrm{b}}}{\mathrm{dl} \mathrm{g}^{-1}}$} \\
\hline $\mathrm{mol} / \mathrm{mol}$ & & & & & & & \\
\hline $3 / 4$ & 1200 & IIIa & 93 & 0.23 & IVa & 86 & 0.31 \\
\hline $7 / 8$ & 2500 & IIIb & 86 & 0.32 & IVb & 90 & 0.39 \\
\hline $12 / 13$ & 4100 & IIIc & 84 & 0.39 & IVc & 90 & 0.61 \\
\hline $15 / 16$ & 5100 & IIId & 83 & 0.40 & IVd & 85 & 0.60 \\
\hline $26 / 27$ & 8800 & IIIe & 86 & 0.43 & IVe & 90 & 0.78 \\
\hline
\end{tabular}

${ }^{a}$ Monomers in the feed.

${ }^{b}$ Measured at a concentration of $0.5 \mathrm{~g} \mathrm{dl}^{-1}$ in DMAc at $30^{\circ} \mathrm{C}$. 
Table II. Solubility of polybutadiene-aramid multi-block copolymers III ${ }^{\mathrm{a}}$

\begin{tabular}{|c|c|c|c|c|c|}
\hline \multirow{2}{*}{ Solvent } & \multirow{2}{*}{ LPB-diacid } & \multicolumn{3}{|c|}{ Copolymer } & \multirow{2}{*}{ Aramid I } \\
\hline & & IIIa & IIIb-IIId & IIIe & \\
\hline$N, N$-Dimethylacetamide & - & + & + & + & + \\
\hline Pyridine & + & + & + & + & + \\
\hline Tetrahydrofuran & + & + & + & \pm & - \\
\hline Benzene & + & \pm & - & - & - \\
\hline Ethyl ether & + & - & - & - & - \\
\hline Hexane & + & - & - & - & - \\
\hline Methanol & - & - & - & - & - \\
\hline
\end{tabular}

a Solubility: + , soluble; \pm , swelling; and - , insoluble.

b Aramid homopolymer derived from 3,4'-ODA and IPA.

\section{Properties of Polybutadiene-Aramid Multi-} Block Copolymers

The qualitative solubility of the multi-block copolymers III and IV in various organic solvents is shown in Table II. As expected, block copolymer III had a wider range of solubility compared with that of copolymers IV. Copolymers III were readily soluble in pyridine which dissolved the parent LPBdiacid and aramid I. Moreover, they were soluble not only in DMAc, a common solvent for aramid I, but also in THF which dissolved only LPB-diacid.

Transparent, ductile and elastomeric films of multi-block copolymers III could be cast from solutions in DMAc, pyridine, and THF. In contrast, the films of block copolymers IV were obtained only from the DMAc solutions.

The solubility behavior of block copolymers III was evaluated in more detail. Inherent viscosities of copolymers III were measured in DMAc, pyridine, and THF. The results are summarized in Table III. It is well known that a solution of polymers in a good solvent has a higher inherent viscosity, while the solution in a poor solvent, a lower viscosity. As obvious from the Table, the best solvent for copolymer IIIa having the highest polybutadiene content was THF and the poorest solvent, DMAc. In contrast, copolymer IIIe with the lowest polybutadiene content was insoluble in THF and the best solvent was DMAc. Pyridine was a
Table III. Inherent viscosities of polybutadiene-aramid multi-block copolymers III in various solvents

\begin{tabular}{lcllll}
\hline & \multirow{2}{*}{ Copolymer } & \multicolumn{2}{c}{ LPB content $^{\mathrm{a}}$} & & \multicolumn{3}{c}{$\eta_{\mathrm{inh}}^{\mathrm{b}} / \mathrm{dlg}^{-1}$} \\
\cline { 5 - 6 } \cline { 5 - 6 } \cline { 5 - 6 } & $\mathrm{wt} \%$ & & DMAc & Pyridine & THF \\
\hline IIIa & 81 & & 0.23 & 0.65 & 1.00 \\
IIIb & 68 & & 0.32 & 0.50 & 0.51 \\
IIIc & 57 & & 0.39 & 0.46 & 0.39 \\
IIId & 50 & & 0.40 & 0.43 & 0.16 \\
IIIe & 37 & & 0.43 & 0.38 & - \\
\hline
\end{tabular}

a Weight (LPB-diacid)/[Weight (LPB-diacid) + Weight (Aramid)] in feed.

b Measured at a concentration of $0.5 \mathrm{~g} \mathrm{dl}^{-1}$ at $30^{\circ} \mathrm{C}$.

moderately good solvent for all block copolymers IIIa-IIIe.

In the next stage, the influence of casting solvents on the micro-structures of the cast films of block copolymers III was investigated with respect to morphology and glass transition temperatures ( $T_{\mathrm{g}}$ 's) of the polybutadiene phase in the block copolymers. The results of $T_{\mathrm{g}}$ measurement by DSC are summarized in Table IV. The unusual depression of the $T_{\mathrm{g}}$ 's of the polybutadiene phase with increasing aramid content in multi-block copolymers IV has been reported. ${ }^{3}$ The same phenomenon was observed in the present case. No appreciable difference in the extent of $T_{\mathrm{g}}$ depression was observed among the casting solvents, DMAc, pyridine, and THF, when the block copolymers having the same aramid content 


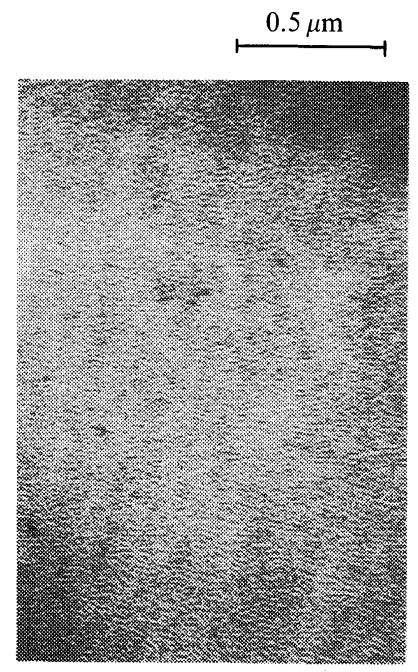

(A)

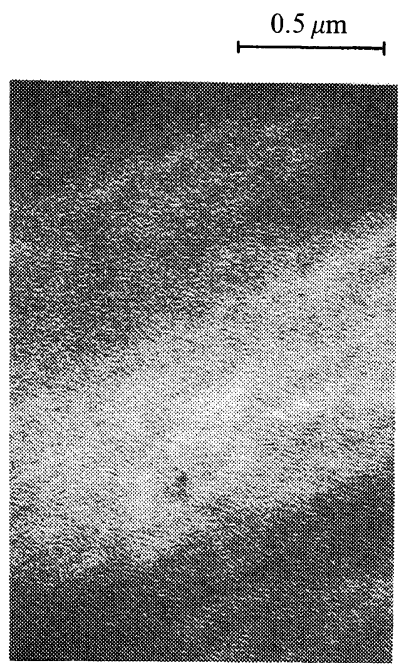

(B)

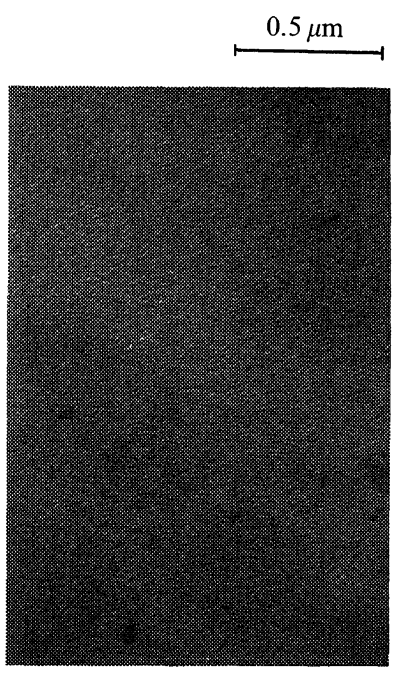

(C)

Figure 1. Transmission electron micrographs $(\times 43000)$ of films of polybutadiene-aramid multi-block copolymer IIId cast from DMAc (A), pyridine (B), and THF (C), and stained with osmium tetraoxide.

Table IV. Glass transition temperatures of films of polybutadiene-aramid multi-block copolymers III cast from various solvents

\begin{tabular}{|c|c|c|c|c|}
\hline \multirow{2}{*}{ Copolymer } & \multirow{2}{*}{$\frac{\text { LPB } \text { content }}{\mathrm{a}}$} & \multicolumn{3}{|c|}{$T_{\mathrm{g}}^{\mathrm{b} /{ }^{\circ} \mathrm{C}}$} \\
\hline & & DMAc & Pyridine & THF \\
\hline IIIa & 81 & -74.5 & -74.0 & -75.0 \\
\hline IIIb & 68 & -74.0 & -74.0 & -75.0 \\
\hline IIIC & 57 & -76.5 & -76.5 & -75.0 \\
\hline IIId & 50 & -78.0 & -77.0 & -77.0 \\
\hline IIIe & 37 & -83.0 & -82.0 & - \\
\hline $\mathrm{PB}^{\mathrm{c}}$ & 98 & -73.5 & - & - \\
\hline
\end{tabular}

a See footnote a of Table III.

${ }^{b}$ Determined by DSC at a heating rate of $20^{\circ} \mathrm{C} \mathrm{cm}^{-1}$ in air.

c Polybutadiene homopolymer derived from LPB-diacid and $p$-phenylenediamine.

were compared. This may be explained by the fact that the films of copolymers III cast from these different solvents had almost the same micro-structures as indicated by transmission electron micrographs (Figure 1).

The relationship between the aramid content ( $M_{n}$ of aramid block) in copolymers III and $\mathrm{IV}$, and the $T_{\mathrm{g}}$, s are shown in Figure 2. The

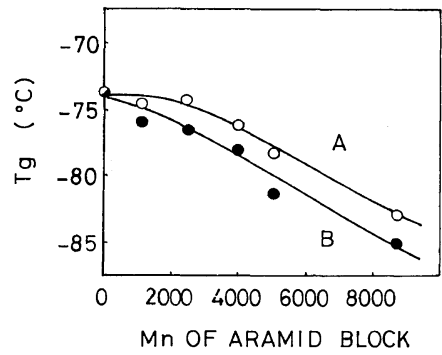

Figure 2. Glass transition temperatures $\left(T_{\mathrm{g}}\right)$ of the polybutadiene phase as a function of molecular weight $\left(M_{n}\right)$ of the aramid block for films of polybutadienearamid multi-block copolymers III (A) and IV (B), cast from DMAc.

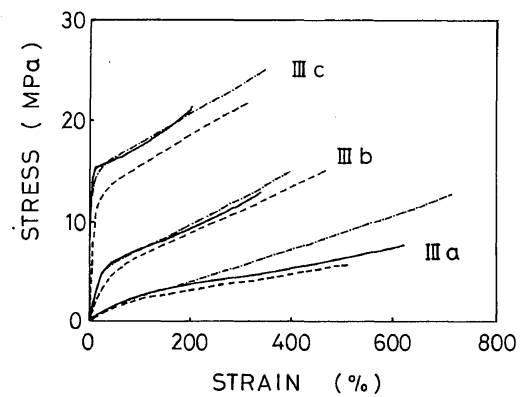

Figure 3. Stress-strain curves for films of polybutadiene-aramid multi-block copolymers III cast from DMAc (-), pyridine (-·-), and THF (-----). 
S. OGata et al.

Table V. Tensile properties of films of polybutadiene-aramid multi-block copolymers III cast from various solvents

\begin{tabular}{|c|c|c|c|c|c|}
\hline \multirow{2}{*}{ Copolymer } & LPB content ${ }^{\mathrm{a}}$ & \multirow{2}{*}{$\begin{array}{l}\text { Casting } \\
\text { solvent }\end{array}$} & \multirow{2}{*}{$\frac{\text { Tensile strength }}{\mathrm{MPa}}$} & \multirow{2}{*}{$\frac{\text { Elongation at break }}{\%}$} & \multirow{2}{*}{$\frac{\text { Initial modulus }}{\mathrm{MPa}}$} \\
\hline & $w t \%$ & & & & \\
\hline IIIa & 81 & DMAc & 7 & 630 & 5 \\
\hline IIIa & 81 & Pyridine & 11 & 720 & 4 \\
\hline IIIa & 81 & THF & 5 & 510 & 4 \\
\hline IIIb & 68 & DMAc & 13 & 340 & 27 \\
\hline IIIb & 68 & Pyridine & 15 & 400 & 32 \\
\hline IIIb & 68 & THF & 15 & 470 & 20 \\
\hline IIIc & 57 & DMAc & 21 & 200 & 420 \\
\hline IIIc & 57 & Pyridine & 25 & 350 & 260 \\
\hline IIIc & 57 & THF & 23 & 320 & 140 \\
\hline IIId & 50 & DMAc & 24 & 100 & 430 \\
\hline IIId & 50 & Pyridine & 29 & 180 & 600 \\
\hline IIId & 50 & THF & 15 & 160 & 190 \\
\hline
\end{tabular}

${ }^{a}$ See footnote a of Table III.

extent of $T_{\mathrm{g}}$ depression for copolymers III was somewhat gradual compared with that for copolymers IV. This is probably due to the less rigid nature of aramid I compared with aramid II.

Stress-strain curves of the films of multiblock copolymers III cast from the solutions in DMAc, pyridine, or THF are shown in Figure 3 , and the tensile properties are summarized in Table V. The films had ductile and elastomeric properties depending markedly on the content of the aramid block which acts as a pseudocrosslinking site. In general, tensile strength and modulus decreased with decreasing aramid content, whereas elongation at break increased.

The influence of the casting solvents on the tensile properties of the films was found to be rather small; however, pyridine, a good solvent for both LPB-diacid and aramid I, showed better tensile properties than DMAc or THF.

A Comparison of the tensile properties of the films of block copolymers III and IV cast from the DMAc solutions is shown in Figure 4. In most cases, block copolymer III had a somewhat lower tensile strength and modulus than block copolymer IV. This is probably due

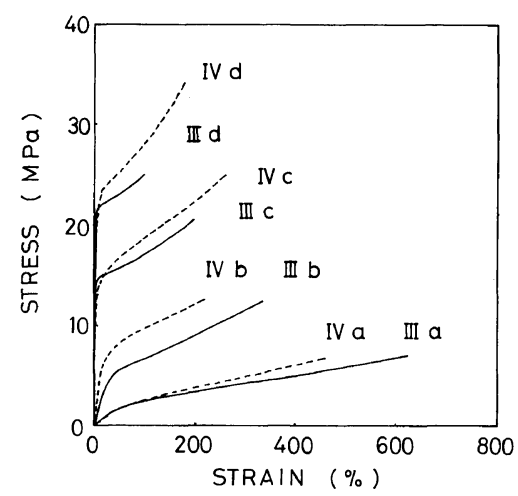

Figure 4. Stress-strain curves for films of polybutadiene-aramid multi-block copolymers III (-) and IV (-----), cast from DMAc.

to the rigidity of the aramid blocks, reflecting the extent of $T_{\mathrm{g}}$ depression discussed above.

Acknowledgment. The authors are indebted to Mr. T. Katsuta of Japan Synthetic Rubber Co. for preparing the transmission electron micrographs, to Professor $\mathrm{S}$. Nakahama for the molecular weight determinations, and to Dr. T. Hashimoto of our Institute for the DSC measurement. We also wish to thank Professor T. Inoue for his helpful comments. 


\section{Polybutadiene-Aramid Multi-Block Copolymers}

\section{REFERENCES}

1. S. Ogata, M. Kakimoto, and Y. Imai, Macromolecules, 18, 851 (1985).
2. Y. Imai, M. Kajiyama, S. Ogata, and M. Kakimoto, J. Polym. Sci., Polym. Chem. Ed., 22, 3183 (1984).

3. T. Inoue, S. Ogata, M. Kakimoto, and Y. Imai, Macromolecules, 17, 1417 (1984). 